\title{
Genetic deficiency of aldose reductase counteracts the development of diabetic nephropathy in C57BL/6 mice
}

\author{
H. Liu $\cdot$ Y. Luo $\cdot$ T. Zhang $\cdot$ Y. Zhang $\cdot$ Q. Wu $・$ \\ L. Yuan • S. S. M. Chung • P. J. Oates - J. Y. Yang
}

Received: 9 September 2010 / Accepted: 10 December 2010 /Published online: 27 January 2011

(C) The Author(s) 2011. This article is published with open access at Springerlink.com

\begin{abstract}
Aims/hypothesis The aim of the study was to investigate the effects of genetic deficiency of aldose reductase in mice on the development of key endpoints of diabetic nephropathy. Methods A line of $A r$ (also known as Akrlb3)-knockout (KO) mice, a line of $A r$-bitransgenic mice and control $\mathrm{C} 57 \mathrm{BL} / 6$ mice were used in the study. The $\mathrm{KO}$ and bitransgenic mice were deficient for $A r$ in the renal glomeruli and all other tissues, with the exception of, in
\end{abstract}

H. Liu, Y. Luo and T. Zhang contributed equally to this study.

Electronic supplementary material The online version of this article (doi:10.1007/s00125-011-2045-4) contains supplementary material, which is available to authorised users.

H. Liu $\cdot$ T. Zhang $\cdot$ Y. Zhang $\cdot$ Q. Wu $\cdot$ L. Yuan $\cdot$ J. Y. Yang $(\bowtie)$ Ministry of Education Key Laboratory for Cell Biology and Tumor Cell Engineering and Department of Biomedical Sciences, School of Life Sciences, Xiamen University,

Xiamen 361005, People's Republic of China

e-mail: jyqy2008@gmail.com

J. Y. Yang

Fujian Provincial Transgenic Core,

Xiamen University Laboratory Animal Centre,

Xiamen, People's Republic of China

Y. Luo

School of Nursing, The Third Military Medical University,

Chongqing, People's Republic of China

S. S. M. Chung

Division of Life Sciences, Graduate School in Shenzhen,

Tsinghua University,

The University Town,

Shenzhen, People's Republic of China

P. J. Oates

Oates Biomedical Consulting,

Gales Ferry, CT, USA the bitransgenic mice, a human $A R$ cDNA knockintransgene that directed collecting-tubule epithelial-cellspecific $A R$ expression. Diabetes was induced in 8-weekold male mice with streptozotocin. Mice were further maintained for 17 weeks then killed. A number of serum and urinary variables were determined for these 25-weekold mice. Periodic acid-Schiff staining, western blots, immunohistochemistry and protein kinase $\mathrm{C}$ (PKC) activity assays were performed for histological analyses, and to determine the levels of collagen IV and TGF- $\beta 1$ and PKC activities in renal cortical tissues.

Results Diabetes-induced extracellular matrix accumulation and collagen IV overproduction were completely prevented in diabetic $A r-\mathrm{KO}$ and bitransgenic mice. $A r$ deficiency also completely or partially prevented diabetes-induced activation of renal cortical PKC, TGF- $\beta 1$ and glomerular hypertrophy. Loss of $A r$ results in a $43 \%$ reduction in urine albumin excretion in the diabetic $A r-\mathrm{KO}$ mice and a $48 \%$ reduction in the diabetic bitransgenic mice $(p<0.01)$. Conclusions/interpretation Genetic deficiency of $A r$ significantly ameliorated development of key endpoints linked with early diabetic nephropathy in vivo. Robust and specific inhibition of aldose reductase might be an effective strategy for the prevention and treatment of diabetic nephropathy.

Keywords Aldose reductase $\cdot$ Collagen IV - Diabetic nephropathy · Oxidative stress · PKC · Polyol pathway · TGF- $\beta 1 \cdot$ Urinary albumin
Abbreviations
AR Aldose reductase
ARI Aldose reductase inhibitor
BT $\quad A R^{-/-} K s p A R^{+/-}$bitransgenic
BUN Blood urea nitrogen 


$\begin{array}{ll}\text { Cit } & \text { Citrate buffer } \\ \text { DN } & \text { Diabetic nephropathy } \\ \text { ECM } & \text { Extracellular matrix } \\ \text { GSH } & \text { Glutathione } \\ \text { KO } & \text { Knockout } \\ \text { MDA } & \text { Malondialdehyde } \\ \text { PAS } & \text { Periodic acid-Schiff } \\ \text { PKC } & \text { Protein kinase C } \\ \text { SOD } & \text { Superoxide dismutase } \\ \text { STZ } & \text { Streptozotocin } \\ \text { UAE } & \text { Urinary albumin excretion } \\ \text { WT } & \text { Wild type }\end{array}$

\section{Introduction}

In the mammalian kidneys, aldose reductase (AR) is abundantly produced in the inner medulla, where it converts glucose to sorbitol, the latter serves as a critical organic osmolyte to protect the collecting duct tubule cells from hyperosmotic insults [1] (the human gene encoding AR is $A K R 1 B 1$ [also known as $A R$ ] and the mouse gene is $A k r l b 3$ [also known as $A r]$ ). In contrast to its prominent expression in the renal medulla, AR production in the renal cortex is low to moderate, depending on cell types. Under normal physiological conditions, AR production in the glomerulus is low. However, a significant increase in glomerular AR production was found in diabetic human patients $[2,3]$. Diabetes in rats led to a tenfold increase in glomerular sorbitol content, whereas sorbitol was unchanged in diabetic rats treated with an aldose reductase inhibitor (ARI), sorbinil [4]. Within the glomerulus, $\mathrm{Ar}$ mRNA expression is strongly induced in the mesangial cells [5, 6] and the endothelial cells [7] under hypertonic conditions. Overactivation of AR in renal cells has been linked with aberrant activation of protein kinase $\mathrm{C}$ (PKC) [8-10], generation of advanced glycation products, increased expression of TGF- $\beta$ and generation of reactive oxygen species [11]. Together these data suggest that significant activation of AR by hyperglycaemia in the renal glomeruli might contribute to the onset or progression of glomerulopathy and diabetic nephropathy (DN).

$\mathrm{AR}$ is the first and the rate-limiting enzyme of the polyol pathway, a pathway that has been implicated in the development of diabetic complications, particularly diabetic retinopathy and diabetic neuropathy $[11,12]$. The association of AR and the polyol pathway with the development of $\mathrm{DN}$, however, is less conclusive, partly because the data obtained from genetic, biochemical, pharmacological, animal and clinical studies have been less consistent [13]. For instance, some human genetic studies support the association of $A R$ 5'-end polymorphism with DN [14-19] while others did not confirm this [19-21]. In one animal model study, transgenic overexpression of human $A R$ in mice led to pathological changes in the kidney, lens and retina [22]. In another communication, however, it was reported that diabetes-induced albuminuria was prevented in transgenic rats overexpressing human $A R$ selectively in the straight (S3) portion of renal proximal tubules [23]. Most pharmacological experiments demonstrated a positive influence of chemically synthesised ARIs on the development of DN in diabetic rats [13, 24-26], but a few failed [27, 28]. Further, although some human clinical trials have reported unchanged glomerular function after ARI treatment [29], encouraging results have also been obtained that clearly demonstrate the beneficial effects of the inhibition of AR with ARIs $[13,30]$.

The reasons for the inconsistency with regard to the pathophysiological roles of $\mathrm{AR}$ and the effectiveness of ARIs in DN are not completely clear. However, incomplete AR inhibition, the presence of multiple AR-like proteins, individual genetic differences and the specificity, side or toxic effects of ARIs are among the possible contributing factors. Studies have shown that human and rodent kidney tissues possess a number of AR-like proteins, such as ARlike gene-1 [31] and renal-specific oxidoreductase [32], as well as renal aldehyde reductases [33]. It is not clear how these structurally and functionally similar proteins might interact in vitro and in vivo. Meanwhile, the specificity of these inhibitors used in animal studies or clinical studies remains open to question. Some of them are already known to be able to inhibit aldehyde reductases, in addition to AR [33]. Such 'off-target' effects might underlie undesired side effects or even toxic effects.

One approach to overcome the shortcomings associated with the use of ARIs is to use a gene-knockout (KO) model. Mice globally deficient in $A r\left(A r^{-/-}\right)$, however, were found to carry defects in the renal medulla characterised by renal medullary atrophy and epithelial cell death $[34,35]$. As a consequence of these medullary lesions, $A r$-deficient mice develop a phenotype resembling that of nephrogenic diabetes insipidus in human $[34,35]$. Because of this problem, no DN study has yet been performed with $A r$ deficient mice, even though they have been available for more than 10 years $[34,36]$; therefore, the data from a gene-knockout model have been lacking. Recently, we created a double-transgenic mouse line $\left(A r^{-/-} K s p A R^{+/-}\right.$ bitransgenic [BT]) that is deficient in AR in all tissues and the kidney glomeruli except in the inner medulla, where an $A R$-knockin transgene is driven by the kidney-specific cadherin promoter to direct $A R$ expression specifically in the collecting tubule epithelial cells [35]. The BT mice differ from the $A r-\mathrm{KO}$ mice in that the $A r$-KO mice are completely deficient in AR whereas the $\mathrm{BT}$ mice are deficient in $\mathrm{AR}$ in all tissues, including most parts of the 
kidney, except the medullary collecting tubule epithelial cells that carry the knockin transgene. The glomeruli from the $A r-\mathrm{KO}$ and $\mathrm{BT}$ mice, however, are equivalent in terms of AR production. As a consequence of the medullary epithelial cell-specific $A R$ expression of the knockin transgene, the cellular lesions in renal medulla and the urine concentrating mechanisms were shown to be significantly corrected in the BT mice [35]. In our current study, we used the $A r-\mathrm{KO}$ and BT mice to investigate the effects of genetic deficiency of $\mathrm{Ar}$ on the development of early DN. Our results indicate that genetic ablation of $A r$ significantly ameliorates the development of DN in streptozotocin (STZ)-induced diabetic C57BL/6 mice.

\section{Methods}

Animals and animal treatments All animal experiments were carried out in accordance with the guidelines of the Xiamen University Institutional Committee for the Care and Use of Laboratory Animals. $A r^{-/-}$mice [34] were prepared and backcrossed with $\mathrm{C} 57 \mathrm{BL} / 6$ mice for seven generations. A line of transgenic mice $\left(K s p A R^{+/}\right)$in which a human $A R$ transgene driven by the mouse kidney-specific cadherin promoter to overproduce AR specifically in the collecting tubule epithelial cells was generated and backcrossed with C57BL/6 mice for six generations as described [35]. Subsequent intercrosses between the KO mice and the $K s p A R^{+/-}$mice generated the BT mice heterozygous for $K s p A R$ and homozygous for the $A r-\mathrm{KO}$ allele $\left(A r^{-/-}\right.$ $K s p A R^{+/-}$), as well as the $A r-\mathrm{KO}$ mice and the wild-type (WT) mice [35]. The genotypes of three groups of mice were verified as described previously by Yang et al. [35]. The KO, BT and WT mice were, therefore, relatively homogeneous for the C57BL/6 background that was maintained as described previously [35]. For each particular genotype, male mice, 8 weeks old, were randomly divided into two subgroups (each having at least six mice): one was intraperitoneally injected with $40 \mathrm{mg} \mathrm{kg}^{-1} \mathrm{day}^{-1}$ for five consecutive days; and the other was injected with a vehicle solution $(0.1 \mathrm{~mol} / \mathrm{l}$ citrate buffer [Cit]). Immediately after the diabetic induction, blood glucose was assayed with a Glucometer (OneTouch Ultra, LifeScan, Milpitas, CA, USA) and only those mice with blood glucose levels above $16 \mathrm{mmol} / \mathrm{l}$ were considered to be diabetic. Six treatment groups of mice were therefore generated. They were: nondiabetic WT (WT + Cit) mice; non-diabetic $\mathrm{KO}(\mathrm{KO}+\mathrm{Cit})$ mice; non-diabetic BT (BT + Cit) mice; diabetic WT (WT + STZ) mice; diabetic KO (KO + STZ) mice; and diabetic BT (BT + STZ) mice. The diabetic and non-diabetic mice were maintained for an additional 17 weeks. The animals were transferred to metabolism cages 1 day before the age of 25 weeks (one mouse/cage, with free access to standard chow diet and water) for $24 \mathrm{~h}$ for urine sample collection. Blood samples were collected by sinus puncture and the animals were subsequently killed and kidneys were dissected for analyses.

PKC activity assays PKC activity assays were carried out with the PepTag Nonradioactive PKC Assay System from Promega (Beijing, China) according to the manufacturer's instructions. Briefly, renal cortical tissues were homogenised in $2 \mathrm{ml}$ ice-cold extraction buffer (supplied) with a Kinematica homogeniser (Lucerne, Switzerland). The homogenates were centrifuged at $100,000 \times g$ and $4^{\circ} \mathrm{C}$ for $60 \mathrm{~min}$. The supernatant fractions were taken as the cytosol fractions whereas the pellets were further dissolved in $2 \mathrm{ml}$ of the extraction buffer with $1 \%$ Triton X-100. After $30 \mathrm{~min}$ incubation at $4^{\circ} \mathrm{C}$, the solutions were centrifuged again at $100,000 \times \mathrm{g}$ for $60 \mathrm{~min}$, and the second supernatant fractions were used as the membrane fractions. The concentrations of protein in the preparations were determined with the BCA Protein Assay Kit (Pierce Biotechnology, Rockford, IL, USA). The membrane and cytoplasmic fractions were then used for PKC activity assays, following the manufacturer's instructions. The phosphorylated and non-phosphorylated reaction mixtures were separated on a $0.8 \%$ agarose gel. The gels were visualised under UV light and the bands were quantified by densitometric analysis using Image-Pro Plus software (Media Cybernetics, Shanghai, China).

Serum analyses, urine analyses, western blots for TGF- $\beta 1$ and collagen IV, immunohistochemistry for renal expression of collagen IV and other renal histological analyses These experimental procedures are described in detail in the Electronic supplementary material (ESM).

Statistical analyses All statistical analyses were performed with the GraphPad Prism. Values are expressed as the means \pm SEM. Multiple group comparisons were performed with one-way ANOVA with the Bonferroni's post test and pair-wise comparisons were performed with unpaired Student's $t$ test. A probability value $<0.05$ was considered to be significant.

\section{Results}

$A R$ deficiency in the Ar-KO and BT mice significantly ameliorated diabetes-induced renal hypertrophy, elevations in serum triacylglycerols and serum LDL-cholesterol and urinary albumin excretion (UAE) To assess the effects of genetic deficiency of $\mathrm{Ar}$ on the development of DN, we treated the $A r-\mathrm{KO}, \mathrm{BT}$ and WT $\mathrm{C} 57 \mathrm{BL} / 6$ mice with multiple low doses of STZ $(40 \mathrm{mg} / \mathrm{kg}$, i.p. for five 
consecutive days) to destroy the mouse pancreatic beta cells and to induce diabetes. After STZ injection, blood glucose levels were determined and only those with blood glucose levels greater than or equal to $16 \mathrm{mmol} / \mathrm{l}$ were considered to be diabetic. Both the STZ-treated mice and the control mice were further maintained for 17 weeks under normal rearing conditions (free access to standard chow and water) to allow the development of diabetic kidney diseases.

At the age of 25 weeks (17 weeks from diabetes onset), diabetic WT mice exhibited typical pathophysiological features of early DN (Table 1). With the exception of serum HDL-cholesterol, the body weight, serum content of triacylglycerol, total cholesterol, LDL-cholesterol, blood urea nitrogen (BUN), GFR and UAE were all significantly altered in diabetic WT mice, manifesting as the development of diabetes or early DN. In the diabetic $A r-\mathrm{KO}$ mice, complete deficiency of AR appeared to result in significant improvement in the ratio of kidney/body weight $(6.80 \pm 0.52$ for diabetic $A r$-KO mice vs $8.20 \pm 0.45$ for diabetic WT mice, $p<0.05)$, serum triacylglycerols $(0.57 \pm 0.07 \mathrm{mmol} /$ 1 for diabetic $A r$-KO mice vs $1.11 \pm 0.18 \mathrm{mmol} / 1$ for diabetic WT mice, $p<0.001)$, serum LDL-cholesterol $(1.16 \pm$ $0.13 \mathrm{mmol} / 1$ for diabetic $A r$-KO mice vs $1.62 \pm 0.13 \mathrm{mmol} /$ 1 for diabetic WT mice, $p<0.05)$ and UAE $(1.49 \pm 0.26 \mu \mathrm{g} /$ $\mathrm{mg}$ creatinine for diabetic $A r$-KO mice vs $2.62 \pm 0.34 \mu \mathrm{g} / \mathrm{mg}$ creatinine for diabetic WT mice, $p<0.001)$. In contrast to these DN-associated variables, the BUN and GFR were not significantly improved in the diabetic $A r$-KO mice. However, in diabetic BT mice, not only the body weight, but the ratio of kidney/body weight, serum triacylglycerols and LDL-cholesterol, and UAE were all significantly improved compared with the diabetic WT mice; BUN (6.28 \pm $0.19 \mathrm{mmol} / \mathrm{l}$ for diabetic BT mice vs $8.75 \pm 0.53 \mathrm{mmol} /$ 1 for diabetic WT mice, $p<0.001)$ and GFR $(0.18 \pm 0.01 \mathrm{l} /$ $24 \mathrm{~h}$ for diabetic BT mice vs $0.12 \pm 0.01 \mathrm{l} / 24 \mathrm{~h}$ for diabetic WT mice, $p<0.05$ ) both also appeared to be significantly improved. In the STZ-treated groups, the three genotypes of diabetic mice all excreted large volumes of urine that were not statistically different. As these volumes of urine were much larger than those in AR-deficiency-induced polyuria, it suggests that hyperglycaemia is the predominant contributing factor for the polyuric phenotype. Together, these biochemical analyses indicate that AR deficiency resulted in improvement of most serum and urinary variables associated with $\mathrm{DN}$ in diabetic $\mathrm{C} 57 \mathrm{BL} / 6$ mice.

AR deficiency in the diabetic Ar-KO and BT mice significantly ameliorated diabetes-induced glomerular hypertrophy, cell proliferation, mesangial expansion and collagen $I V$ expression To examine for potential renal cortical morphological differences in the diabetic WT mice and the AR-deficient diabetic mice, we performed periodic acid-Schiff (PAS) staining with the renal cortical tissues dissected from six treatment groups of mice at the age of 25 weeks. As shown in Fig. 1a, no apparent difference in glomerular morphology was observed for three nondiabetic genotype groups of mice. The glomeruli were of normal size and configuration for non-diabetic WT, $A r-\mathrm{KO}$ and BT mice. Further, there was no sign of mesangial matrix expansion, inflammation or sclerosis in these mice. In contrast to the findings in these non-diabetic mice, very significant glomerular hypertrophy, increased cellularity and narrowing of capillary lumens was observed in the cortex/glomeruli of diabetic WT mice (Fig. 1a). Further, the mesangium was diffusively and markedly expanded with PAS-positive (purple colour) matrix material. When the digital images of about 30 glomeruli for each genotype were quantitatively analysed, the extracellular matrix $(\mathrm{ECM})$ accumulation index for the diabetic WT mice was, on average, $41 \%$ higher than that for the non-diabetic WT mice $(0.099 \pm 0.002$ for diabetic WT vs $0.070 \pm 0.003$ for non-diabetic WT, $p<0.01$, Fig. $1 \mathrm{~b}$ ), whereas the glomerular size for the diabetic WT on average was $68 \%$ higher than that for the non-diabetic WT mice $(1,733 \pm 13.9$ for diabetic WT vs $1,031 \pm 36.7$ for non-diabetic WT, $p<0.001$, Fig. 1 c). These results indicate significant lesions in renal cortical/ glomerular structures in the WT diabetic mice at the age of 25 weeks. Interestingly, in the glomeruli of diabetic $A r-\mathrm{KO}$ and BT mice, diabetes-induced glomerular hypertrophy, cell proliferation and mesangial matrix expansion were all significantly corrected (Fig. 1a-c). Despite the exposure to hyperglycaemia for 17 weeks, glomerular size and ECM accumulation and configuration in the diabetic $A r-\mathrm{KO}$ and BT mice were almost indistinguishable from those in the non-diabetic mice, characterised by improved glomerular hypertrophy, reduced cellularity and normalisation of mesangial expansion (Fig. 1a-c). These results indicated significant restoration in the renal cortical/glomerular structures as a consequence of genetic deficiency of $\mathrm{Ar}$.

In contrast to the significant differences in the cortex/ glomeruli areas, the outer medullary areas did not show apparent histomorphological differences among genotype groups of mice as determined by PAS staining (ESM Fig. 1). In the inner medulla, however, severe tubular atrophy was observed for all three genotype groups of diabetic mice. The tubulointerstial lesions in the diabetic BT mice, however, appeared to be slightly improved (ESM Fig. 2) as compared with the diabetic $A r$-KO mice.

As collagen IV is the principal protein of the expanded ECM in the diabetic renal glomeruli [37, 38], we analysed the production of collagen IV by immunohistochemistry and western blot. As shown in Fig. 2, in non-diabetic WT mice, relatively low collagen IV production was found in the mesangial cells, the Bowman's capsule and the tubule basement membranes. In strong contrast to this, very prominent collagen IV production was found in the cortical 


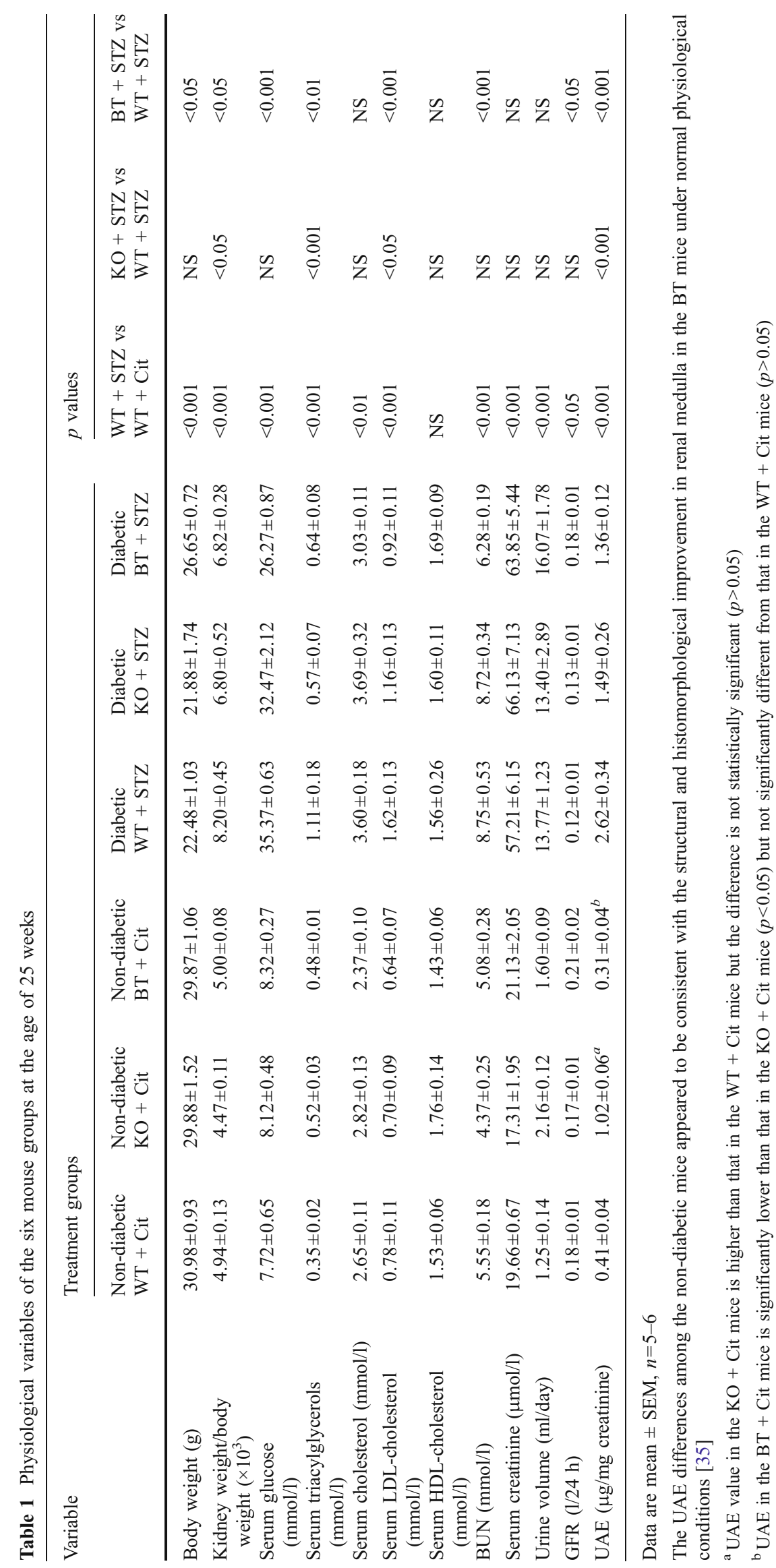


Fig. 1 The effects of genetic deficiency of $\mathrm{Ar}$ on the pathohistological development of DN in the renal cortex and glomerulus as determined by PAS staining. a Renal cortex and glomerulus morphology in six treatment groups of mice at the age of 25 weeks as determined by PAS staining. The results were typical of three mice for each treatment group. Original magnification $\times 1,000$; scale bar, $25 \mu \mathrm{m}$. b Quantitative analyses of ECM accumulation index in six treatment groups of mice. Values were expressed as the mean \pm SEM, $n=3 ; * p<0.05$, $* * p<0.01$. c Quantitative analyses of glomerular sizes in six treatment groups of mice. Glomerular area was determined as described in the Methods.

Values are expressed as the mean \pm SEM, $n=3 ;{ }^{*} p<0.05$, ${ }^{* *} p<0.01, * * * p<0.001$

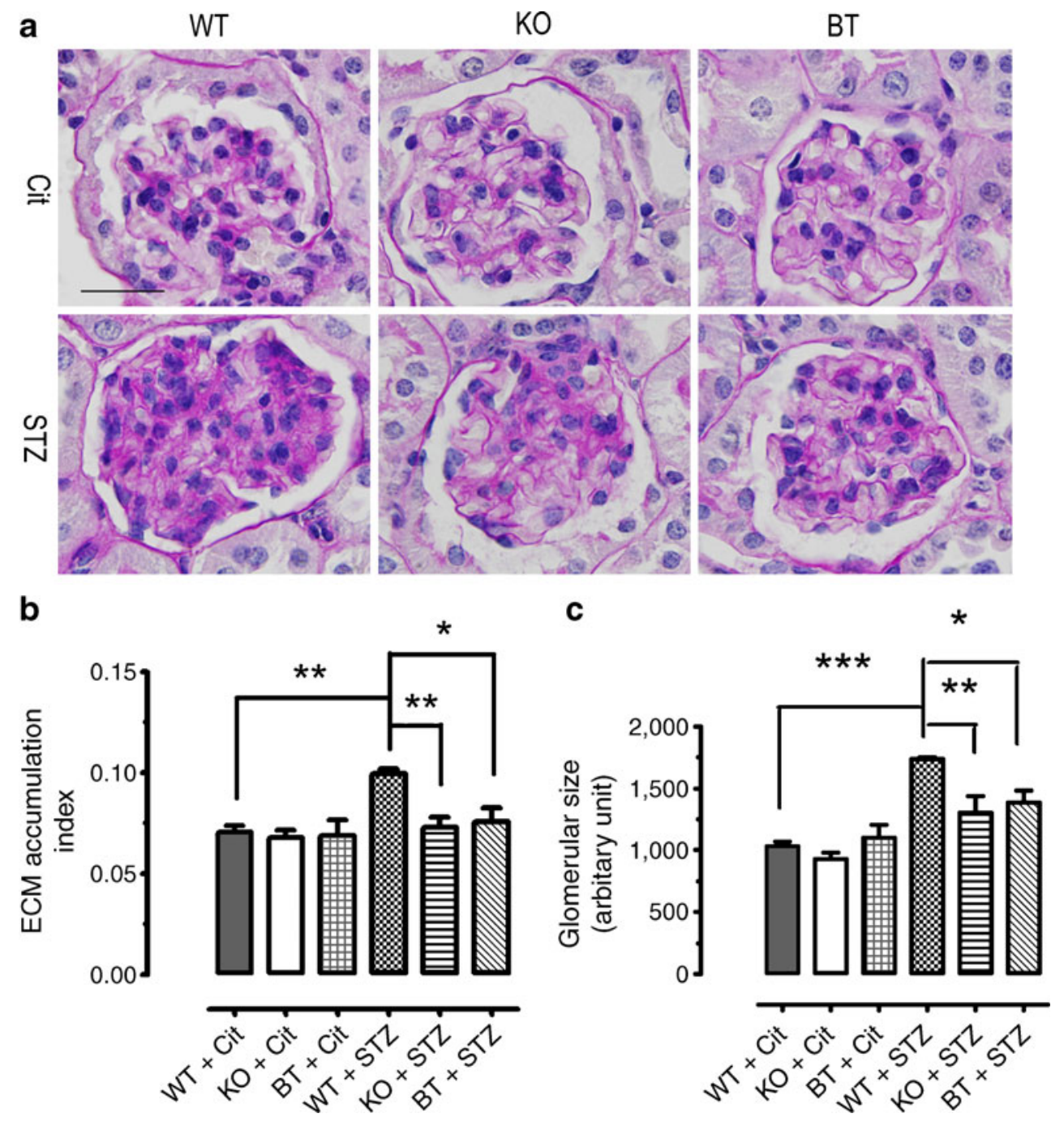

tissues of the diabetic WT mice in both the intraglomerular cells and extraglomerular cells. In $A r$-deficient mice, however, renal cortical collagen IV production was significantly reduced in both the $A r-\mathrm{KO}$ and BT mice, with the reduction in the glomerular expression being more apparent (Fig. 2a). Western blots of renal cortical tissues further verified the trends of collagen production in diabetic WT, $A r-\mathrm{KO}$ and BT mice (Fig. 2b), suggesting that AR deficiency, in glomeruli in particular, led to significant reductions in diabetes-induced overproduction of collagen IV in the glomeruli.

AR deficiency appears to slightly ameliorate diabetesinduced oxidative stress in the renal cortex Recent studies suggest that $\mathrm{DN}$ might be closely linked to oxidative stress $[39,40]$ and that overactivation of $\mathrm{AR} /$ polyol pathway contributes significantly to hyperglycaemia-induced oxidative/nitrosative stress [41, 42]. We therefore performed assays to determine glutathione (GSH) and malondialdehyde (MDA) content and the superoxide dismutase (SOD) activity for renal cortical tissues ( $n=3$ per group) in the six study groups of mice (ESM Fig. 3). When the data for all six treatment groups of mice were analysed with one-way ANOVA, no significant difference in GSH or MDA content or SOD activity between genotype groups was observed for either non-diabetic or diabetic mice, which is probably largely because of the limited number of mice. Despite this, pair-wise comparisons showed that the renal cortical GSH was depleted by $\sim 68 \%$ in $\mathrm{WT}+\mathrm{STZ}$ mice vs $\mathrm{WT}+\mathrm{Cit}$ mice ( $p<0.05$, Student's $t$ test), manifesting as a significant depletion in GSH consistent with hyperglycaemia-induced oxidative stress. Interestingly, GSH appeared to be partially corrected to $\sim 72 \%$ and $\sim 65 \%$ of the normal level in the diabetic $A r-\mathrm{KO}$ and BT groups, respectively, although the results with $n=3$ per group were not statistically significant. An apparent rise in cortical MDA content in the diabetic cortex, also consistent with excess oxidative stress in the diabetic vs non-diabetic cortex, was also seen in WT + STZ mice vs WT + Cit mice, and an apparent correction was seen in the diabetic $A r$-KO mice but not in the diabetic BT mice. In contrast to GSH and MDA, SOD activity showed no trend towards change in any of the groups. Together 
Fig. 2 Collagen IV production in the renal cortex and glomerulus in six treatment groups of mice at the age of 25 weeks. a Collagen IV production in renal cortex and glomerulus in six treatment groups of mice as determined by immunohistochemistry. Original magnification $\times 1,000$; scale bar, $50 \mu \mathrm{m}$. The results were typical of three mice for each treatment group. b Collagen IV production in renal cortex in six treatment groups of mice as determined by western blots. Each lane represents an independent sample. Protein loading was calibrated using $\beta$ actin

\section{a}
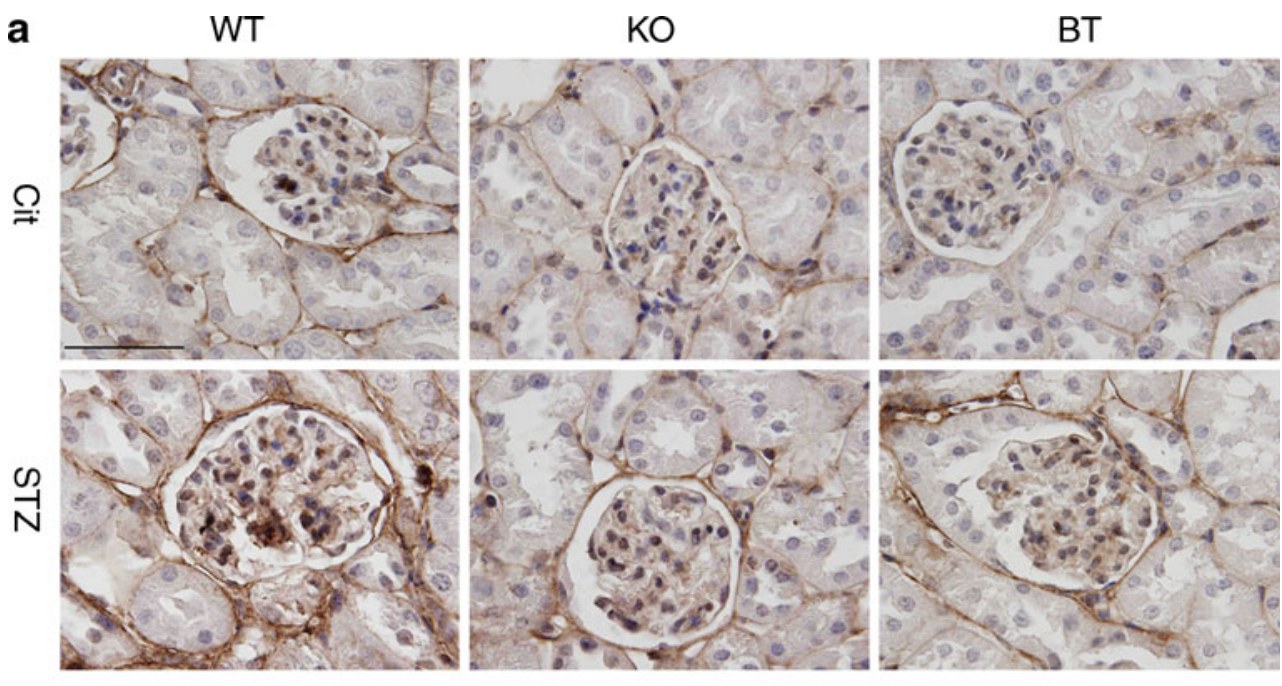

b

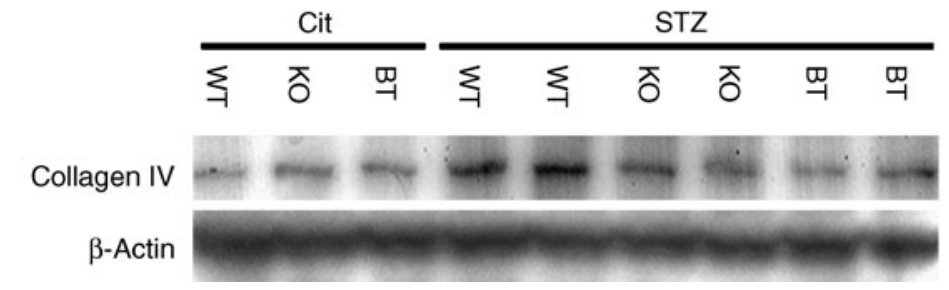

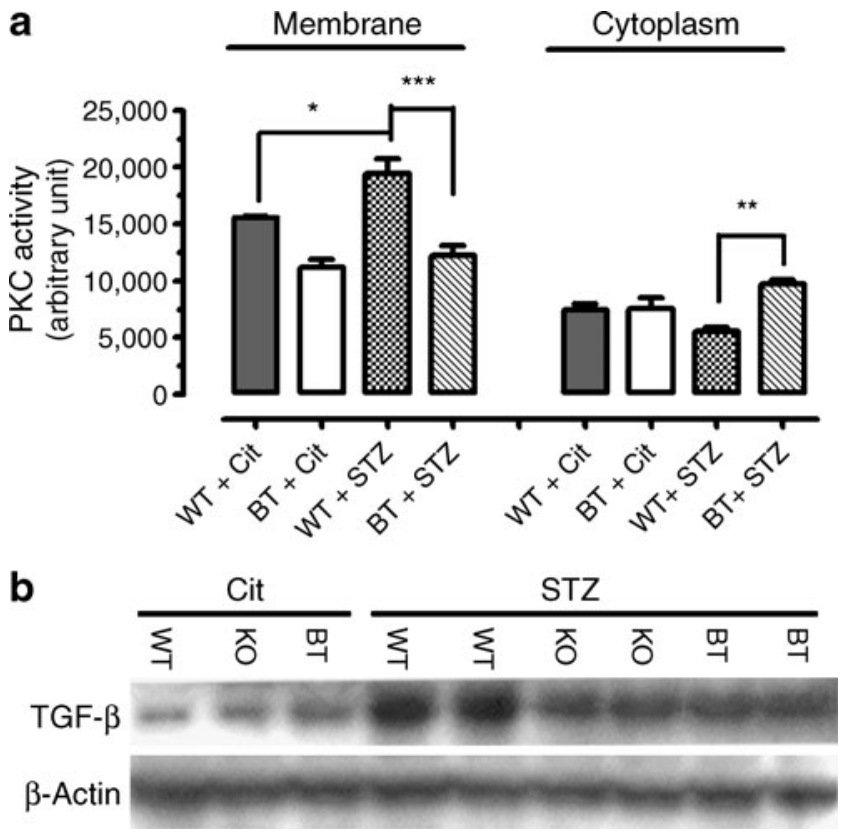

Fig. 3 Effects of $A r$ genetic deficiency on PKC activity and the production of TGF- $\beta 1$. a Membrane and cytosolic PKC activities in the renal cortex of four treatment groups of mice at the age of 25 weeks. Values were expressed as the mean \pm SEM, $n=3 ;{ }^{*} p<0.05$, $* * p<0.01,{ }^{* * *} p<0.001$. b TGF- $\beta 1$ production in the renal cortex in six treatment groups of mice at the age of 25 weeks as determined by western blots. Each lane represents an independent sample. Protein loading was calibrated using $\beta$-actin these data are, in general, consistent with the presence of oxidative stress in the renal cortex of the diabetic vs the non-diabetic state, with a corrective effect of AR deficiency on hyperglycaemia-induced oxidative stress.

AR deficiency in the diabetic $K O$ and $B T$ mice caused significant alterations in PKC activity and TGF- $\beta 1$ production in the renal cortex Previous studies have established that the overactivation of PKC and TGF- $\beta 1$ plays an important role in the development of DN. Among other roles, the PKC-TGF- $\beta 1$ axis is involved in renal fibrogenesis by regulating the production of a number of components for mesangial expansion. To find out how the genetic deficiency of $\mathrm{Ar}$ might affect PKC, we determined PKC activity in the cytosolic and membrane fractions of renal cortical homogenates from four treatment groups of mice (i.e. non-diabetic WT and BT mice and diabetic WT and BT mice). As shown in Fig. 3a, 17 weeks of diabetes caused a $24.8 \%$ elevation in the renal cortical membrane PKC activity in the BT mice $(19,446 \pm 1,311$ for diabetic WT mice vs $15,572 \pm 144$ for non-diabetic WT mice, $p<$ $0.05)$, whereas the cytosolic PKC activity was reduced by about $25 \%$, although this was not statistically significant. In Ar-deficient BT mice, however, the diabetes-induced elevation of membrane PKC and downregulation of cytosolic PKC were largely reversed. For the membrane PKC, $A r$ deficiency caused a $37 \%$ reduction $(19,446 \pm 1,311$ for diabetic WT mice vs $12,189 \pm 918$ for diabetic BT mice, $p<0.001)$. For cytosolic PKC, $A r$ deficiency caused a $75 \%$ 
increase $(5,534 \pm 366$ for diabetic WT mice vs $9,685 \pm 341$ for diabetic BT mice, $p<0.01)$. Together these results indicate that genetic $A r$ deficiency significantly affected renal cortical PKC activity.

We further performed western blots to analyse renal cortical TGF- $\beta 1$ production in non-diabetic and diabetic mice. As shown in Fig. 3 b, moderate levels of TGF- $\beta 1$ protein were detected in non-diabetic WT, KO and BT mice. Seventeen weeks of diabetes, however, greatly upregulated renal cortical TGF- $\beta 1$ production in the diabetic WT mice. In contrast, in both the diabetic $A r-\mathrm{KO}$ and BT mice, TGF- $\beta 1$ production was significantly reduced and the reduction of TGF- $\beta 1$ production is consistent with reduced collagen IV expression in the AR-deficient mice. These data thus suggest that $A r$ deficiency contributes significantly to the amelioration in the development of $\mathrm{DN}$ in the diabetic $\mathrm{Ar}$ $\mathrm{KO}$ and BT mice in part through suppressing diabetesinduced activation of TGF- $\beta 1$.

\section{Discussion}

As mentioned earlier, a large body of animal and clinical studies using chemically synthesised ARIs has yielded mixed results. As the use of genetic knockout models might avoid the potential problems associated with the incomplete AR inhibition, non-specific inhibition or other side effects of ARIs, these models are crucial for the more definitive elucidation of the role of $\mathrm{AR}$ in $\mathrm{DN}$ and of the potential utility of $A R$ inhibition in the prevention or treatment of DN. Consistent with the positive findings of studies using ARIs [13, 24, 25, 43-46], we showed in our current study that the genetic deficiency of $\mathrm{Ar}$ in both the diabetic $\mathrm{KO}$ mice and the diabetic BT mice resulted in significantly reduced UAE, mesangial matrix expansion and reduced overexpression of collagen IV, and improved glomerular hypertrophy. Further, consistent with previous observations $[10,44]$, we demonstrated that $A r$ deficiency was associated with significant attenuation in renal cortical PKC activity and TGF- $\beta 1$ production. In addition, $A r$ deficiency significantly ameliorated diabetes-induced renal hypertrophy and elevations in serum triacylglycerols and serum LDLcholesterol. Together these data clearly imply that hyperglycaemia-induced overactivation of AR and elevation in metabolic flux through the polyol pathway in the renal cortex and the glomeruli contributes significantly to the development of early DN and that inhibition of AR or blockade of the polyol pathway in the renal cortex or the glomeruli might be an effective approach for the prevention or treatment of DN.

Although $A r$ deficiency resulted in ameliorations in a number of important variables associated with DN in both the diabetic $A r-\mathrm{KO}$ and diabetic BT mice, there were a few variables (including serum glucose, BUN and GFR) that characteristically distinguished the diabetic BT mice from the diabetic $A r-\mathrm{KO}$ mice. Somewhat surprisingly, the level of BUN in diabetic $A r-\mathrm{KO}$ mice at the age of 25 weeks was indistinguishable from that of the diabetic WT mice. In diabetic BT mice, however, BUN was $77 \%$ normalised $(6.28 \pm 0.19 \mathrm{mmol} / 1$ for diabetic BT vs $8.75 \pm 0.53 \mathrm{mmol} / 1$ for diabetic WT, $p<0.001)$, suggesting much improved glomerular function for the diabetic BT mice. The reasons for these differences between the diabetic $A r-\mathrm{KO}$ mice and the diabetic BT mice are not clear but are probably linked to the corrections in Ar-deficiency-induced renal medullary defects brought about by the re-introduction of renal collecting tubule epithelial-specific production of AR.

PKC signalling has been shown to play critical regulatory roles in the development of DN in experimental models [8]. Because excessive metabolic flux through AR and the polyol pathway is associated with elevation of cytoplasmic NADH/NAD ${ }^{+}$and diacylglycerol, the latter being a second messenger for PKC, overactivation of $\mathrm{AR}$ has been linked with abnormal activation of PKC [9, 11, 47]. Keogh et al. have reported that AR inhibition prevented glucose-induced prostaglandin synthesis and PKC activation [47]. Using the ARI epalrestat, Ishii et al. have also demonstrated that inhibition of AR blocked glucose-induced increases in PKC and TGF- $\beta 1$ activity in cultured human mesangial cells [10]. Our demonstration that genetic deficiency of $\mathrm{Ar}$ led to a decrease in membrane $\mathrm{PKC}$ activity but an increase in the cytosolic PKC is consistent with the results from AR inhibition by ARIs. While the mechanisms for the membrane-cytoplasm redistribution of $\mathrm{PKC}$ require further investigation, there now remains no doubt that inhibition of $\mathrm{AR}$ is a way to suppress glucose-induced overactivation of PKC in the kidneys.

TGF- $\beta 1$ is a multifunctional cytokine capable of regulating cell proliferation, differentiation, motility, apoptosis, immune cell function and ECM formation. Currently, this pro-sclerotic protein is recognised as the major cytokine responsible for mesangial expansion, ECM accumulation and vascular dysfunction and glomerulosclerosis in DN [48, 49]. Previous studies have shown that glucoseinduced TGF- $\beta 1$ is polyol pathway dependent $[10,50]$ and that inhibition of AR leads to suppressed production of TGF- $\beta$ [10] and collagen IV [44] and reduced mesangial expansion [45]. The suppression of renal cortical TGF- $\beta$, collagen IV and mesangial expansion brought about by ARIs is now further recapitulated with the genetic mouse models deficient in $A r$ in our current investigation. Normalisation of TGF- $\beta 1$ activity due to $A R$ deficiency thus is likely to contribute significantly to the amelioration of $\mathrm{DN}$ in the $A r-\mathrm{KO}$ and BT mice. 
Acknowledgements This work was supported in part by grants from the National Science Foundation of China (\#30770490); the 973 Program of China (\#2009CB941601); the Science Planning Program of Fujian Province (\#2009J1010) and the Natural Science Foundation of Fujian Province (\#2009J01180) and the Fujian Provincial Department of Science and Technology (\#2010L0002).

Duality of interest The authors declare that there is no duality of interest associated with this manuscript.

Open Access This article is distributed under the terms of the Creative Commons Attribution Noncommercial License which permits any noncommercial use, distribution, and reproduction in any medium, provided the original author(s) and source are credited.

\section{References}

1. Burg MB, Kador PF (1988) Sorbitol, osmoregulation, and the complications of diabetes. J Clin Invest 81:635-640

2. Corder CN, Braughler JM, Culp PA (1979) Quantitative histochemistry of the sorbitol pathway in glomeruli and small arteries of human diabetic kidney. Folia Histochem Cytochem 17:137145

3. Kasajima H, Yamagishi S, Sugai S, Yagihashi N, Yagihashi S (2001) Enhanced in situ expression of aldose reductase in peripheral nerve and renal glomeruli in diabetic patients. Virchows Arch 439:46-54

4. Beyer-Mears A, Ku L, Cohen MP (1984) Glomerular polyol accumulation in diabetes and its prevention by oral sorbinil. Diabetes 33:604-607

5. Kaneko M, Carper D, Nishimura C, Millen J, Bock M, Hohman TC (1990) Induction of aldose reductase expression in rat kidney mesangial cells and Chinese hamster ovary cells under hypertonic conditions. Exp Cell Res 188:135-140

6. Kikkawa R, Umemura K, Haneda M et al (1992) Identification and characterization of aldose reductase in cultured rat mesangial cells. Diabetes 41:1165-1171

7. Hohman TC, Carper D, Dasgupta S, Kaneko M (1991) Osmotic stress induces aldose reductase in glomerular endothelial cells. Adv Exp Med Biol 284:139-152

8. Noh H, King GL (2007) The role of protein kinase C activation in diabetic nephropathy. Kidney Int Suppl 106:S49-S53

9. Kapor-Drezgic J, Zhou X, Babazono T, Dlugosz JA, Hohman T, Whiteside C (1999) Effect of high glucose on mesangial cell protein kinase C-delta and -epsilon is polyol pathway-dependent. J Am Soc Nephrol 10:1193-1203

10. Ishii $\mathrm{H}$, Tada $\mathrm{H}$, Isogai $\mathrm{S}$ (1998) An aldose reductase inhibitor prevents glucose-induced increase in transforming growth factorbeta and protein kinase $\mathrm{C}$ activity in cultured mesangial cells. Diabetologia 41:362-364

11. Oates PJ, Mylari BL (1999) Aldose reductase inhibitors: therapeutic implications for diabetic complications. Expert Opin Investig Drugs 8:2095-2119

12. Chung SS, Chung SK (2005) Aldose reductase in diabetic microvascular complications. Curr Drug Targets 6:475-486

13. Oates PJ (2010) Aldose reductase inhibitors and diabetic kidney disease. Curr Opin Investig Drugs 11:402-417

14. So WY, Wang Y, Ng MC et al (2008) Aldose reductase genotypes and cardiorenal complications: an 8-year prospective analysis of 1,074 type 2 diabetic patients. Diab Care 31:2148-2153

15. Heesom AE, Hibberd ML, Millward A, Demaine AG (1997) Polymorphism in the $5^{\prime}$-end of the aldose reductase gene is strongly associated with the development of diabetic nephropathy in type I diabetes. Diabetes 46:287-291

16. Moczulski DK, Burak W, Doria A et al (1999) The role of aldose reductase gene in the susceptibility to diabetic nephropathy in type II (non-insulin-dependent) diabetes mellitus. Diabetologia 42:94-97

17. Neamat-Allah M, Feeney SA, Savage DA et al (2001) Analysis of the association between diabetic nephropathy and polymorphisms in the aldose reductase gene in type 1 and type 2 diabetes mellitus. Diabet Med 18:906-914

18. Shah VO, Scavini M, Nikolic J et al (1998) Z-2 microsatellite allele is linked to increased expression of the aldose reductase gene in diabetic nephropathy. J Clin Endocrinol Metab 83:2886-2891

19. Xu M, Chen X, Yan L, Cheng H, Chen W (2008) Association between (AC)n dinucleotide repeat polymorphism at the 5'-end of the aldose reductase gene and diabetic nephropathy: a metaanalysis. J Mol Endocrinol 40:243-251

20. Moczulski DK, Scott L, Antonellis A et al (2000) Aldose reductase gene polymorphisms and susceptibility to diabetic nephropathy in type 1 diabetes mellitus. Diabet Med 17:111-118

21. Maeda S, Haneda M, Yasuda H et al (1999) Diabetic nephropathy is not associated with the dinucleotide repeat polymorphism upstream of the aldose reductase (ALR2) gene but with erythrocyte aldose reductase content in Japanese subjects with type 2 diabetes. Diabetes 48:420-422

22. Yamaoka T, Nishimura C, Yamashita K et al (1995) Acute onset of diabetic pathological changes in transgenic mice with human aldose reductase cDNA. Diabetologia 38:255-261

23. Ng DP, Hardy CL, Burns WC et al (2002) Prevention of diabetesinduced albuminuria in transgenic rats overexpressing human aldose reductase. Endocrinology 18:47-56

24. Beyer-Mears A, Mistry K, Diecke FP, Cruz E (1996) Zopolrestat prevention of proteinuria, albuminuria and cataractogenesis in diabetes mellitus. Pharmacology 52:292-302

25. McCaleb ML, McKean ML, Hohman TC, Laver N, Robison WG $\mathrm{Jr}$ (1991) Intervention with the aldose reductase inhibitor, tolrestat, in renal and retinal lesions of streptozotocin-diabetic rats. Diabetologia 34:695-701

26. Tilton RG, Chang K, Pugliese G et al (1989) Prevention of hemodynamic and vascular albumin filtration changes in diabetic rats by aldose reductase inhibitors. Diabetes 38:12581270

27. Daniels BS, Hostetter TH (1989) Aldose reductase inhibition and glomerular abnormalities in diabetic rats. Diabetes 38:981-986

28. Faiman G, Ganguly P, Mehta A, Thliveris JA (1993) Effect of statil on kidney structure, function and polyol accumulation in diabetes mellitus. Mol Cell Biochem 125:27-33

29. McAuliffe AV, Brooks BA, Fisher EJ, Molyneaux LM, Yue DK (1998) Administration of ascorbic acid and an aldose reductase inhibitor (tolrestat) in diabetes: effect on urinary albumin excretion. Nephron 80:277-284

30. Pedersen MM, Christiansen JS, Mogensen CE (1991) Reduction of glomerular hyperfiltration in normoalbuminuric IDDM patients by 6 mo of aldose reductase inhibition. Diabetes 40:527-531

31. Cao D, Fan ST, Chung SS (1998) Identification and characterization of a novel human aldose reductase-like gene. J Biol Chem 273:11429-11435

32. Wallner EI, Wada J, Tramonti G, Lin S, Srivastava SK, Kanwar YS (2001) Relevance of aldo-keto reductase family members to the pathobiology of diabetic nephropathy and renal development. Ren Fail 23:311-320

33. Barski OA, Gabbay KH, Grimshaw CE, Bohren KM (1995) Mechanism of human aldehyde reductase: characterization of the active site pocket. Biochemistry 34:11264-11275

34. Ho HT, Chung SK, Law JW et al (2000) Aldose reductasedeficient mice develop nephrogenic diabetes insipidus. Mol Cell Biol 20:5840-5846 
35. Yang JY, Tam WY, Tam S et al (2006) Genetic restoration of aldose reductase to the collecting tubules restores maturation of the urine concentrating mechanism. Am J Physiol Renal Physiol 291:F186-F195

36. Aida K, Ikegishi Y, Chen J et al (2000) Disruption of aldose reductase gene (Akr1b1) causes defect in urinary concentrating ability and divalent cation homeostasis. Biochem Biophys Res Commun 277:281-286

37. Cohen MP, Lautenslager GT, Shearman CW (2001) Increased urinary type IV collagen marks the development of glomerular pathology in diabetic $d / d b$ mice. Metabolism 50:1435-1440

38. Steffes MW, Bilous RW, Sutherland DE, Mauer SM (1992) Cell and matrix components of the glomerular mesangium in type I diabetes. Diabetes 41:679-684

39. Forbes JM, Coughlan MT, Cooper ME (2008) Oxidative stress as a major culprit in kidney disease in diabetes. Diabetes 57:1446-1454

40. Kashihara N, Haruna Y, Kondeti VK, Kanwar YS (2010) Oxidative stress in diabetic nephropathy. Curr Med Chem $17: 4256-4269$

41. Obrosova IG (2005) Increased sorbitol pathway activity generates oxidative stress in tissue sites for diabetic complications. Antioxid Redox Signal 7:1543-1552

42. Drel VR, Pacher P, Stevens MJ, Obrosova IG (2006) Aldose reductase inhibition counteracts nitrosative stress and poly(ADPribose) polymerase activation in diabetic rat kidney and highglucose-exposed human mesangial cells. Free Radic Biol Med 40:1454-1465
43. Cohen MP (1986) Aldose reductase, glomerular metabolism, and diabetic nephropathy. Metabolism 35:55-59

44. Dan Q, Wong RL, Yin S, Chung SK, Chung SS, Lam KS (2004) Interaction between the polyol pathway and non-enzymatic glycation on mesangial cell gene expression. Nephron Exp Nephrol 98:e89-e99

45. Itagaki I, Shimizu K, Kamanaka Y et al (1994) The effect of an aldose reductase inhibitor (Epalrestat) on diabetic nephropathy in rats. Diabetes Res Clin Pract 25:147-154

46. Donnelly SM, Zhou XP, Huang JT, Whiteside CI (1996) Prevention of early glomerulopathy with tolrestat in the streptozotocin-induced diabetic rat. Biochem Cell Biol 74:355362

47. Keogh RJ, Dunlop ME, Larkins RG (1997) Effect of inhibition of aldose reductase on glucose flux, diacylglycerol formation, protein kinase $\mathrm{C}$, and phospholipase A2 activation. Metabolism $46: 41-47$

48. Sharma K, McGowan TA (2000) TGF-beta in diabetic kidney disease: role of novel signaling pathways. Cytokine Growth Factor Rev 11:115-123

49. Zhu Y, Usui HK, Sharma K (2007) Regulation of transforming growth factor beta in diabetic nephropathy: implications for treatment. Semin Nephrol 27:153-160

50. Wong TY, Phillips AO, Witowski J, Topley N (2003) Glucosemediated induction of TGF-beta 1 and MCP-1 in mesothelial cells in vitro is osmolality and polyol pathway dependent. Kidney Int 63:1404-1416 